\title{
BACIS THEORETICAL CHARACTERISTICS OF INTERNAL CONTROL
}

\author{
Firdaus I. Kharisova ${ }^{1}$ \\ Alisa V. Samoilova ${ }^{2}$
}

\begin{abstract}
The question of the existence of an effective internal control system is now of particular relevance. The current stage of the economic entities operation in the Russian Federation is a stage of changing the external and internal environment of management, characterized by a high level of uncertainty and instability, which consists in toughening of competitive relations. Domestic organizations have to operate in the conditions of rapid change and development of technologies, a tough competitive environment, growing business diversification, and inconsistency of domestic legislation. One of the main factors for creating the competitiveness of organizations is effective management, based on quality, reliable and complete information
\end{abstract}

about the managed facility. The paper reveals key questions about the internal control of commercial organizations in the non-financial sector. The main interpretations of the term "internal control" and components of the internal control system are considered, the stages of internal control formation are outlined, the place of internal control in a corporate governance system is substantiated, and official powers in the internal control system are identified. Also, the authors present the main documents which should be noted when studying the issue of internal control. The main methods used in this work are the information systematization, processing and generalization.

\footnotetext{
${ }^{1}$ Kazan Federal University, Institute of Management, Economics and Finance, e-mail: firdavsun@mail.ru

${ }^{2}$ Kazan Federal University, Institute of Management, Economics and Finance, e-mail: samoilowa.alis@mail.ru
} 
Key words: internal control system, components of the internal control system, evolution of internal control, delineation of powers within the internal control system.

\section{INTRODUCTION}

For a long time, the term "internal control" was associated exclusively with accounting activities. The essence of internal control was the verification carried out by the accountants in order to identify errors and facts of fraud. In fact, the English word "control" comes from an understanding of the essence of ancient accounting control, which consisted in bilateral fixation of transactions and verification of their correlation.

In the second half of the twentieth century, the internal control system in organizations began to be considered as a starting point for conducting external audits carried out by independent companies representing the interests of shareholders. The introduction of internal control allowed an independent auditor who found that controls were working well, spend less time searching for evidence from other sources to assess the reliability of the company's financial statements [6].

With the expansion of companies' activities, their complication, as well as computerization, the importance of internal control as an element of external control grows. At the present stage, the necessity of introduction of the internal control system is enshrined in legislation. So in the Russian Federation, the issue of internal control in organizations is disclosed in Article 19 of the Federal Law No. 402 "On Accounting": an economic entity which accounting (financial) statements are subject to obligatory audit, is obliged to organize and carry out internal control of accounting records maintenance and preparation of accounting (financial) statements [1].

The evolution of the

$\begin{array}{lr}\text { term } & \text { control" } \\ \text { understanding } & \text { is } \\ \text { schematically } & \text { presented } \\ \text { below. } & \end{array}$




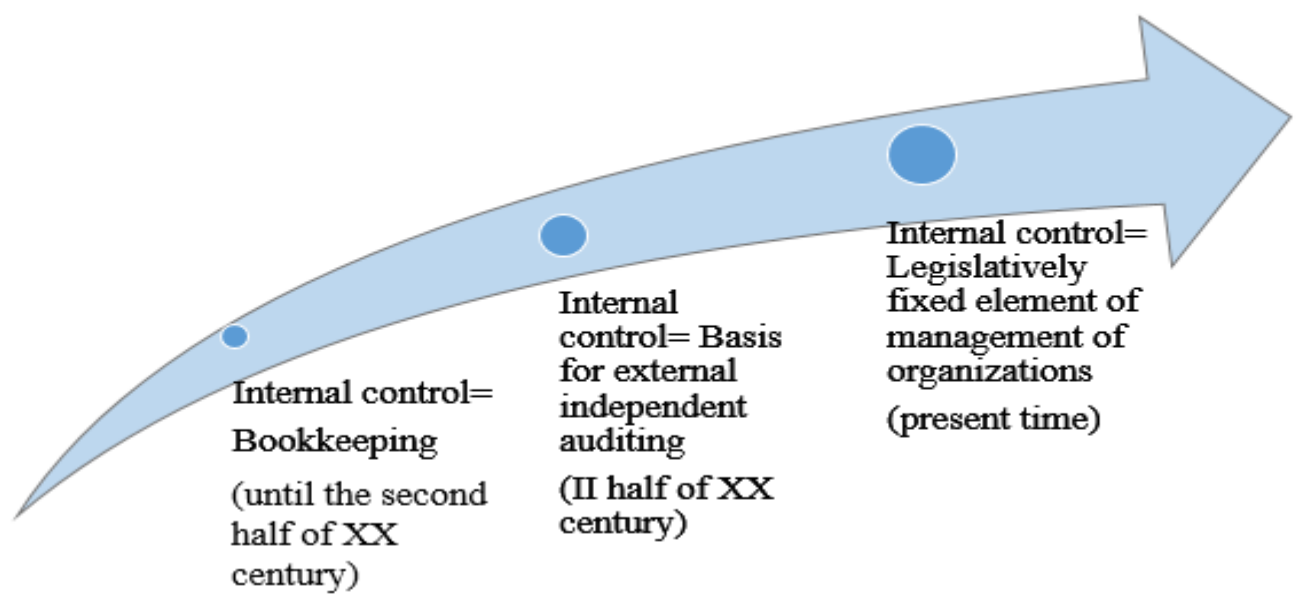

Fig. 1. The scheme proposed by the authors "Evolution of the term "internal control" understanding

\section{Materials and Methods}

Currently, there are various interpretations of the term "internal control". The definition of internal control in the territory of the Russian Federation is reflected in the letter of the Ministry of Finance PZ-11/2013 "Organization and implementation by economic entities of internal control of the operations which concern economic life, and also accounting records maintenance and preparation of accounting (financial) statements": internal control is the process aimed at obtaining sufficient confidence that the economic entity provides:

a) Efficiency and effectiveness of its activities, including the achievement of financial and operational indicators, and the safety of assets;

b) Reliability and timeliness of accounting (financial) and other reporting;

c) Compliance with the applicable law, including in the case of committing economic life operations and accounting records maintenance [2].

In 1992, the Committee of Sponsoring Organizations of the 
Treadway Commission (Eng. COSO) issued a document containing a definition of internal control. According to this definition, internal control is a process designed to provide a reasonable guarantee of achieving control in three areas:

$$
\text { Efficiency and }
$$

effectiveness of operations;

- Reliability of financial statements;

- Compliance with existing laws and regulations [4].

In accordance with the International Standard on Auditing (ISA) 315, "Identifying and Assessing the Risks of Material Misstatement through Understanding the Entity and Its Environment", internal control is the processes developed, implemented and maintained by persons responsible for corporate governance, by management and by other employees of the organization to ensure reasonable assurance about the achievement of the organization's objectives in the preparation of sound financial reporting, efficiency and effectiveness of activity, and also compliance with applicable laws and regulations [3].

According to the federal rule (standard) of auditing (FR(S)A) No. 8 , the internal control system is a process organized and implemented by representatives of the owner, corporate management, and other employees of the audited entity in order to ensure sufficient confidence in achieving the goals from the point of view of the reliable financial (accounting) statements, the effectiveness and efficiency of business operations and the compliance of the entity's activities with regulatory legal acts. This means that organization of the internal control system and its functioning are aimed at eliminating any risks of economic activity that threaten achievement of any of these goals [2].

Comparing and putting together the approaches considered to the interpretation of the essence of internal control in a similar way, we came to the conclusion that they are supplemented by the opinion of $\mathrm{R}$. Hightower, who noted that the 
internal control system provides reasonable guarantees and supervision over the processes that:

- establish the parameters for the delegation of authority and regulation of economic activity in accordance with the requirements of regulatory legal acts, internal policies and procedures;

- test and report compliance with the established parameters;

- evaluate operational efficiency and effectiveness;

- assess the reliability of financial statements;

- report on compliance with applicable laws and regulations;
- support compliance with the limits of authority [7].

Next, we consider the place of internal control in an organization. M. Leitch in his book "Internal Control and Risk Management" introduced internal control as the basis for making management decisions at the organization level [8]. The vision of Matthew Leitch regarding the place of internal control in the management of the company is presented in Scheme 2.

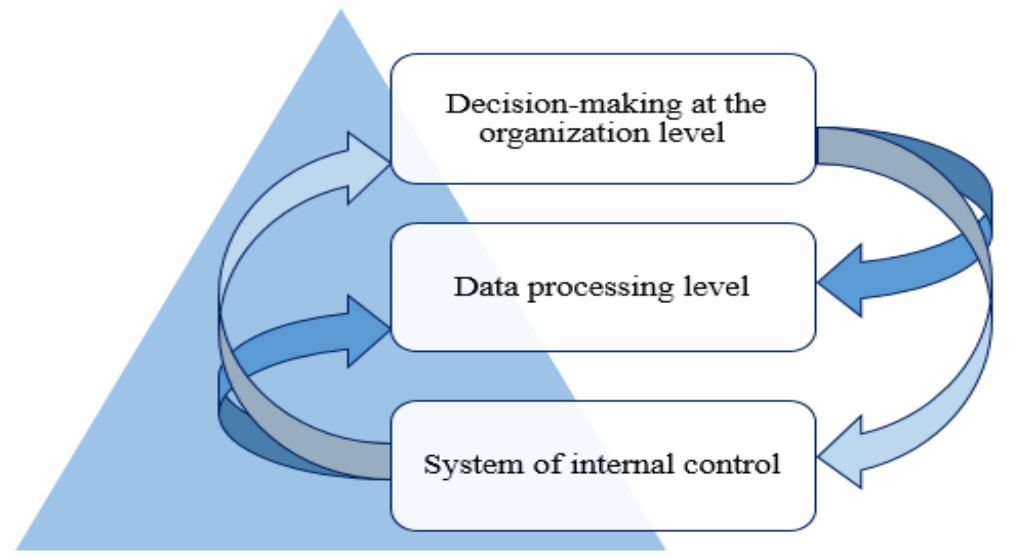

Fig. 2. The place of internal control in an organization

Like any system, internal practice, it is customary to control includes a number of distinguish the following elements components. In international 
of internal control as presented in

Scheme 3.

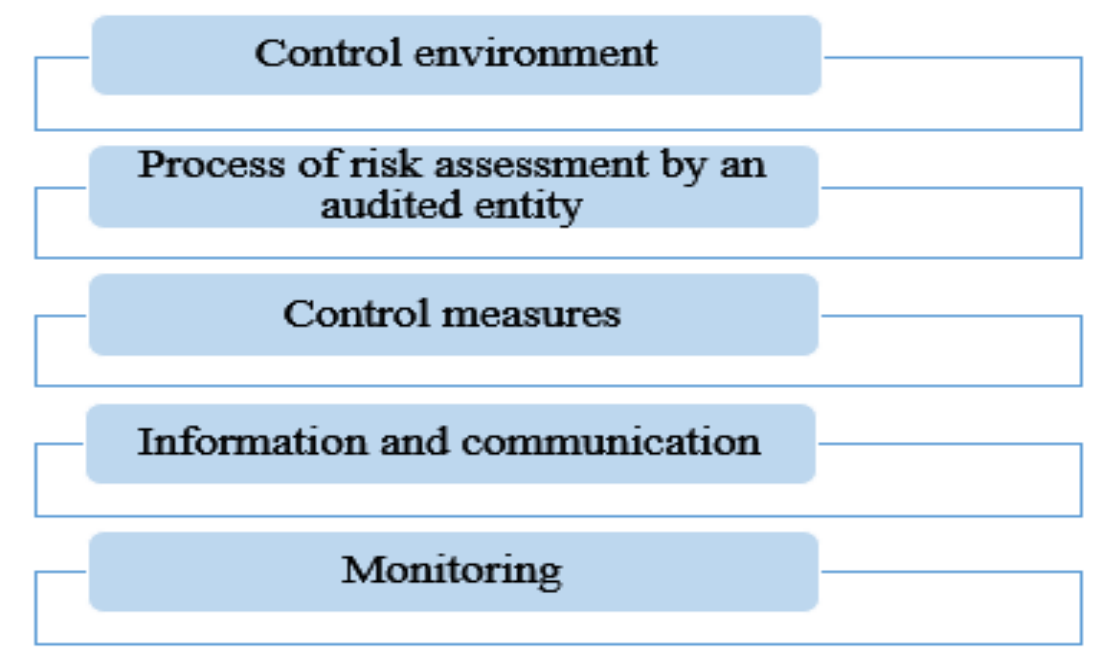

Fig. 3. Components of internal control

Let's consider each of these components in more detail.

1. The control environment. It is a general characteristic of the organization, policies and procedures regarding internal control. It is developed by the company management and includes the following elements:

The organizational structure of internal control, including the distribution of powers, as well as the accountability of subjects of internal control;
- Style and philosophy of company management;

- Personnel policy;

- Ethical qualities of people taking part in the evaluation of the internal control system [6].

2. Risk assessment by the entity being audited is the process of identifying and, if possible, eliminating the risks of economic activity, as well as their possible consequences [2].

3. Control measures. It is necessary to justify the quality implementation of management orders and to implement measures 
that reduce risk situations. Control measures include:

- Comparison of actual data with expected data and data of previous periods;

- Processing of information with regard to the general significant means of control to ensure that the transactions comply with the current legislation, and is fully and correctly reflected;

Distribution of responsibilities for controlling operations, their accounting and maintenance of property safety in order to reduce the risks of fraud;

- Carrying out of inventories and comparison of actual property with accounting data.

4. Information and communication. These are ways to convey information to employees of all levels and distribute it in a form that supports the achievement of the organization's goals. A widely used method of information distribution in the modern world is computer technologies that ensure the storage and exchange of information in a timely and necessary form. Means of communication can also be written and oral.

5. Monitoring. This includes observation for the process on assessment of the internal control organization, the structure and timely operation of control subjects, as well as making decisions on the implementation of the necessary adjustments [9].

Hightower R. distinguishes in the definition given above the separation of powers in order to implement internal control procedures as an important element of the system. In our opinion, the element of clear division of powers in the internal control system should be specified separately, since understanding specifically of its field of activity should lead to the effective functioning of the internal control system, which underlines the importance of this component. We consider the delineation of powers under the Committee of Sponsoring Organizations of the Treadway Commission, which is presented in Table 1. 
Table 1. Delineation of powers in an internal control system under the Tradewill Commission [5].

\begin{tabular}{|c|c|}
\hline Position & Credentials \\
\hline CEO & $\begin{array}{l}\text { Responsible for the organization of the internal control } \\
\text { system as a whole. Creates an environment for the } \\
\text { functioning of internal control, which reflects its } \\
\text { importance, integrity and ethical principles. }\end{array}$ \\
\hline Board of Directors & $\begin{array}{l}\text { Establishes corporate policies within the organization. } \\
\text { Is responsible for the adequacy and effectiveness of the } \\
\text { internal control system. Is obliged to take appropriate } \\
\text { actions in case of receiving information on the } \\
\text { shortcomings of the internal control system. Provides } \\
\text { resources for the implementation and monitoring of the } \\
\text { internal control system. }\end{array}$ \\
\hline Top management & $\begin{array}{l}\text { Provides reports in time for the implementation and } \\
\text { effectiveness of the internal control system. }\end{array}$ \\
\hline Internal auditors & $\begin{array}{l}\text { Assess effectiveness of the internal control system. } \\
\text { They give recommendations on how to improve it. }\end{array}$ \\
\hline $\begin{array}{l}\text { Heads } \\
\text { departments }\end{array}$ & $\begin{array}{l}\text { Establish and monitor specific points concerning the } \\
\text { internal control of the entrusted department. }\end{array}$ \\
\hline Employees & $\begin{array}{l}\text { Carry out their duties within the prescribed system of } \\
\text { internal control. }\end{array}$ \\
\hline Third parties & $\begin{array}{l}\text { Provide useful information on improving the internal } \\
\text { control system (for example, external auditors). }\end{array}$ \\
\hline
\end{tabular}

In practice, it is very difficult to clearly distinguish between the limits of authority. This is demonstrated by the table considered above, where you can see duplication of authority. For example, the General Director and the Board of Directors are responsible for the overall effectiveness of the internal control 
system organization and, banking and insurance organizations consequently, for the elimination of shortcomings identified. Internal auditors and third parties (external auditors) carry out activities to assess the internal control system and make appropriate proposals for its improvement.

\section{Results and their Discussion}

Having considered key points regarding the internal control system in an enterprise, it can be concluded that the introduction of an effective system of internal control leads to the adoption of decisions that contribute to the achievement of the goals set by the organization. The importance of internal control is emphasized at the legislative level, where the mandatory availability of an internal control system for a number of companies is enshrined and implementation for all business entities is recommended.

This paper focuses on the system of internal control of commercial organizations in the non-financial sector. The main provisions on internal control of can be found in the documents below. Concerning the banking sphere [10]:

- Federal Law dated 02. 12. 1990 No. 395-1 (ed. of 2013) "On Banks and Banking Activities";

- Document of the Basel Committee on Banking Supervision "Principles for the Improvement of Corporate Governance", October 2010 (CBR Letter No. 14-T dated 06. 02. 2012);

- Documents of the Basel Committee on Banking Supervision (letter of the Central Bank of Russia dated 13. 05. 2002 N 59-T);

- Document of the Basel Committee on Banking Supervision, September 1998, (letter of the Central Bank of the Russian Federation dated 10. 07. 2001 No. 87-T);

- Document of the Basel Committee on Banking Supervision, April 2005, (CBR Letter No. 173-T dated 02. 11. 2007); 
- Document of the International Association of Insurance Supervisors (letter of the Bank of Russia dated 10. 08. 2016 N IN-015-53 / 60).

Regarding organizations operating in the sphere of rendering insurance services:

- Law of the Russian Federation dated 27. 11. $1992 \mathrm{~N}$ 4015-1 (as amended in 2013) "On the organization of insurance business in the Russian Federation".

\section{Summary}

Modern conditions cause a qualitative change of all the levers of enterprise management. One of the most important components of the system for the adoption and implementation of an effective management decision is internal control, which acquires in modern conditions the character of a foundation that is present at all levels of government. Effective internal control contributes to the achievement of a quality management result providing managers with timely information. In accordance with this, internal control at the enterprise is focused mainly on providing the basic performance indicators in modern conditions: the stable position of the organization in the industry markets, the timely adaptation of the organization's production and management systems to the permanently changing external environment, the recognition of the organization by market entities and the public. In a broad sense, an effective system of internal control in a competitive environment is a guarantee of the successful operation of an organization.

\section{ACKNOWLEDGEMENTS}

The work is carried out according to the Russian Government Program of Competitive Growth of Kazan Federal University.

\section{REFERENCES}

Federal Law on Accounting dated 06. 12. 2011 No. 402 - FZ (as 
amended on December 28, 2013), Article 19.

Federal Rule (Standard) of Auditing Activities (FR (S) AA) No. 8, paragraphs 41-42.

Document No. PZ-11/2013, the letter of the Ministry of Finance of the Russian Federation dated 25. 12. 2013 No. 07-04-15 / 57289, item 3.

International Standard on Auditing (ISA) 315 "Identification and assessment of risks of material misstatement by examining the organization and its environment", item 4.

A document issued by the Committee of Sponsoring Organizations of the Tradway Commission (Eng. COSO).

Hassan A.M. Effects of internal control system of the organizational performance. Journal of Business Management / Vol.2, Issue 9, Sept 2016, p. 153-167.
Hightower, Rose. Internal Controls

Policies and Procedures.Hightower, Rose John Wiley \& Sons, Incorporated 2008, p. 39-40.

Leitch, Matthew. Intelligent Internal Control and Risk Management: Designing High - Performance Risk Control Systems. Leitch, Matthew/Taylor and Francis, 2008, p.15-16.

Sanusu F, Bashir M. The effectiveness of internal control system and financial accountability. International Journal of Research in Business Management / Vol.3, Issue 8, Aug 2015, p.1-6.

The Institute of Internal Auditors site. URL: https://www. iia-ru. ru/.

Naumova N.A., Kharisova F.I. Effective internal audit service organisation in health clinics. Mediterranean Journal of Social Sciences/ Vol.5, Issue 24, 2014, p.170-175 